\title{
Our sigmoid colon volvulus experience and benefits of colonoscope in detortion process
}

\author{
M. Turan, M. Sen ${ }^{1}$, K. Karadayi, A. Koyuncu, O. Topcu, C. Yildirir ${ }^{1}$ and M. Duman \\ University Faculty of Medicine. Department of General Surgery. Sivas, Turkey. ${ }^{1}$ Faculty of Medicine. Department of \\ General Surgery. Cumhuriyet University. Sivas, Turkey. ${ }^{2}$ German Hospital. Department of General Surgery. Istanbul, \\ Turkey
}

\begin{abstract}
Background/aims: the sigmoid colon is the most frequent site for a volvulus. In this report, we review our experience with sigmoid colon volvulus.

Methodology: we present our experience of 81 cases of sigmoid volvulus admitted to our department.

Results: preoperative endoscopic volvulus detortion was attempted in all patients, and in 39 of them the procedure was successful. The success rate of endoscopic detortion for sigmoid colon volvulus with a flexible colonoscope $(60 \%)$ was higher than with a rigid rectosigmoidoscope (42\%). In 19 of these 39 nonoperatively devolvulated patients, sigmoid resection with primary anastomosis was performed within 7-10 days after reduction, but 20 patients did not accept the elective operation after a non-operative treatment. Among the 61 patients undergoing urgent or elective operation for sigmoid volvulus, there were 17 laparotomies laparatomies with only detortion, 19 resections with elective anastomosis, 6 resections with primary anastomosis, and 19 resections with a Hartmann's pouch. There were 9 deaths (21\%) among 42 patients who underwent an emergency operation, and one $(5.2 \%)$ among the 19 patients who had elective surgery died because of a cerebral embolus.

Conclusions: initial therapy with endoscopy affords decompression and an adequate preparation of patients for surgical resection, and a flexible colonoscope has notable advantages over rigid instruments for the detortion process.
\end{abstract}

Key words: Sigmoid colon. Volvulus. Detortion.

Turan M, Sen M, Karadayı K, Koyuncu A, Topcu O, Yıldırır C, Duman M. Our sigmoid colon volvulus experience and benefits of colonoscope in detortion process. Rev Esp Enferm Dig 2004; 96: 32-35.

Recibido: 23-04-03.

Aceptado: 29-07-03.

Correspondencia: Mustafa Turan. Gokcebostan Mah. Gonul Sok. Hurriyet Apt. D. No: 2.58050 Sivas, Turkey. e-mail: mturan_1999@yahoo.com

\section{INTRODUCTION}

Sigmoid colon volvulus, defined as an abnormal twisting of the sigmoid colon around its mesentery, is an infrequent cause of colonic obstruction. It is relatively rare in Western countries. Bolt found only 28 cases admitted to three British hospitals over a 10-year period (1). In the United States it accounts for 3-5 percent of all cases of intestinal obstruction (2). In the Middle East sigmoid volvulus is four times as common as in Western countries (3). Dietary fermentation and gas production contributes to the etiology of sigmoid volvulus. It generally occurs in elderly patients who often have a serious coexisting disease, and has a high mortality when surgically treated (4). Non-operative reduction alone is associated with a high recurrence rate (5). Considerable controversy exists regarding the best method of treatment in the acute situation.

Our university hospital is in an endemic area for sigmoid volvulus, and this paper was undertaken to analyze the experience of our clinic in sigmoid volvulus.

\section{METHODOLOGY}

Between 1982 and 2002, 81 of 424 patients with acute intestinal obstruction from Cumhuriyet University's Department of General Surgery, Sivas, Turkey, had sigmoid colon volvulus. The diagnosis was made from the history, physical examination, plain abdominal radiograph, and emergency barium enema. The following parameters were assessed: age, sex, previous diagnosis, symptoms and signs, diagnostic modalities employed, surgical procedure, pathologic findings, length of hospital stay, complications, and mortality.

Endoscopic procedures were carried out on all patients with suspected sigmoid colon volvulus. Between 1982 and 1994, detortion procedures in this series were perfor- 
med using a rigid rectosigmoidoscope, whereas between 1995 and 2002 these procedures were performed with a colonoscope (Fig. 1); if the detortion procedure was successful and the sigmoid mucosa was normal, a long, soft $18 \mathrm{~F}$ rectal tube was placed within the volved segment with a rigid rectosigmoidoscope, and patients were prepared for elective resection. If the mucosa was necrotic and gangrenous, then the detortion process was stopped.

\section{RESULTS}

There were $61(75.3 \%)$ men and $20(24.6 \%)$ women with a mean age of 65 years (range 21-85 years), men being slightly younger than women (58 years versus 65 years). Seventy-one percent of patients were 50 years or older, and 38 percent were over 70 .

The duration of symptoms ranged from 20 hours to 8 days (average 1.7 days). Patients under 50 years presented earlier (average 1.1 days). All patients complained of abdominal pain and inabiliy to discharge gas or stools. Other complaints reported included constipation $(39.5 \%)$, nausea $(27.1 \%)$, vomiting $(20.9 \%)$, and diarrhea
(9.8\%). On physical examination, the most consistent finding was abdominal distension (95.0\%). Localized tenderness was present in $34(41.9 \%)$ patients, and there was generalized tenderness in $10(13 \%)$. Fever and leucocytosis were present in $77(95.0 \%)$ patients in the absence of another source of infection. The rectum was empty on digital examination in 76 cases (93.8\%). An inflated sigmoid appears as an inverted U-shaped, sausage-like loop. Preoperative endoscopic volvulus detortion was attempted in all patients. Between year 1982-1994 detortion procedures were succesfully performed in 24 of $56(42 \%)$ patients with rigid rectosigmoidoscope but in three patients this procedure was complicated with perforation of the colon. Between 1995-2002 detortion procedures were succesfully performed in 15 of 25 (60\%) patients with colonoscope and there wasn't any complication related with the detortion procedure.

In 19 of these 39 non-operatively devolvulated patients, a sigmoid resection with a primary anastomosis was performed within 7-10 days after reduction, but 20 patients did not accept an elective operation after their non-operative treatment. Although no regular follow-up was made, three of these cases had recurrence and surgery.

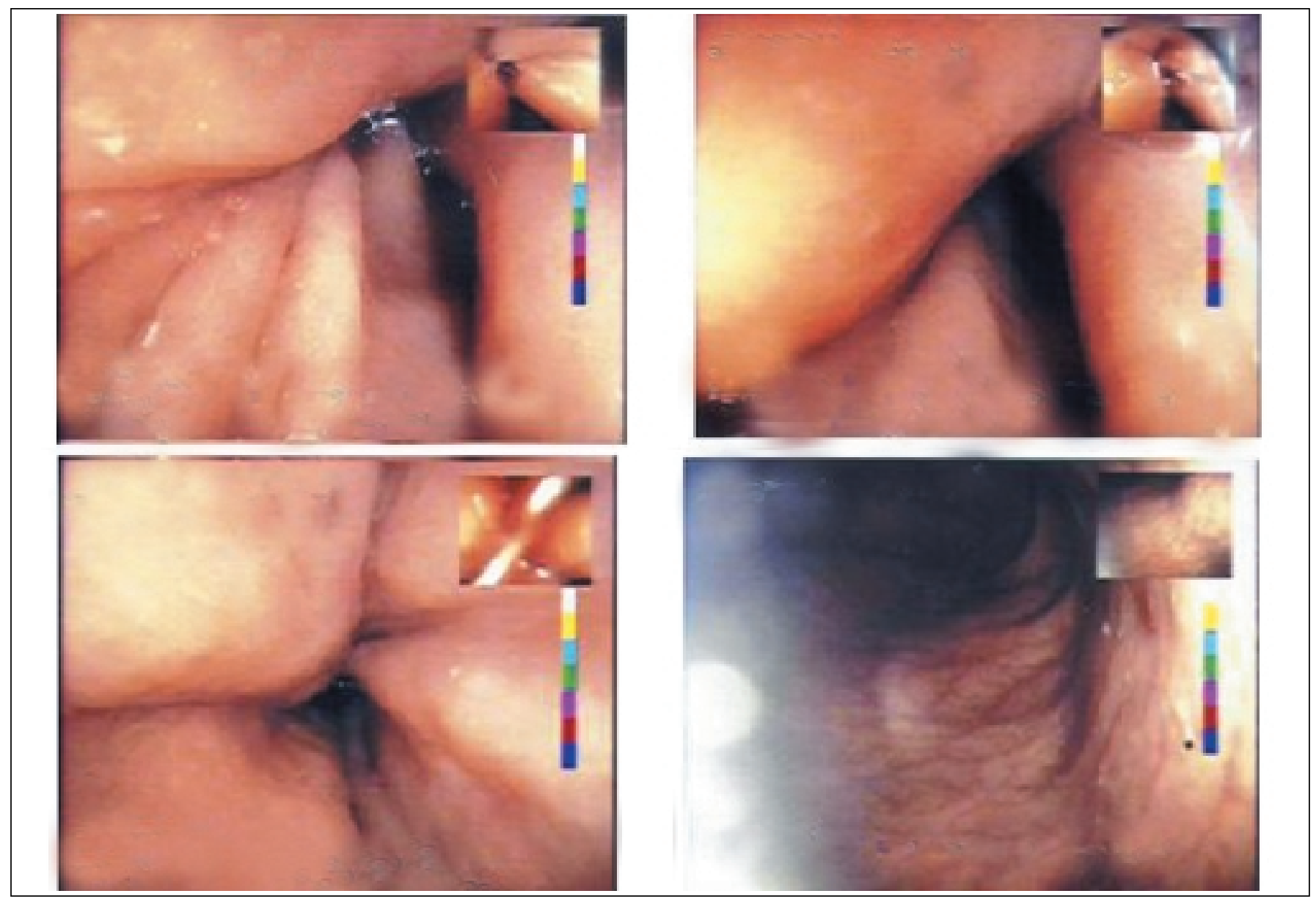

Fig. 1.- The first three pictures show the detortion phase of an acute sigmoid colon volvulus, and the last picture shows the dilated lumen of a volvulated sigmoid colon. 
Operative findings of patients are shown in table I. Among the 61 patients undergoing urgent or elective operation for sigmoid volvulus, there were 17 laparatomies with only detortion, 19 resections with elective anastomosis, 6 resections with primary anastomosis, and 19 resections with a Hartmann's pouch. In those cases various postoperative complications were observed (Table II).

The most commonly seen complication was wound infection.

In the group having emergency operations, there were 4 deaths in patients who were operatively detortioned, one death in patients with resection and primary anastomosis, and 4 deaths in patients with a Hartmann's pouch. A review of the results shows 9 deaths (21\%) among 42 patients who underwent an emergency operation. One (5.2\%) of the 19 patients who had elective surgery died because of a cerebral embolus. There were no deaths in patients who were successfully decompressed and then followed non-operatively.

Table I. Operative findings in our patients

\begin{tabular}{lc}
\hline Findings & Number of cases \\
\hline Sigmoid colon & 14 \\
$\quad$ Edema & 9 \\
Gangrena & 2 \\
Perforation & 8 \\
Peritonitis & 6 \\
Adhesions & 3 \\
Gangreneous ileum & \\
\hline
\end{tabular}

\section{DISCUSSION}

Volvulus of the sigmoid colon occurs more commonly in older persons and particularly in psychiatric or senile patients in nursing homes. Two factors are indispensable for the development of volvulus: a) a redundant segment of colon with a short mesentery; and b) a close proximity of the point of fixation to the segment. The sigmoid flexure with a redundant loop is the most frequent site of colonic volvulus. Torsion in the sigmoid colon results in obstruction, and the proximal colon distends with air and fluid. The resulting increase in intraluminal pressure progressively compromises venous and then arterial flow. It is important to recognize this condition early and then initiate prompt treatment. A high mortality (30 to 50\%) occurs in patients with gangrenous changes or in elderly patients with concomitant disease of the cardiovascular, respiratory or renal system (6).

As in other neighboring countries, the rate of colon volvulus causing intestinal obstruction is high in Turkey $(7,8)$, and it was $19.1 \%$ in this study. Chronic constipation, congenital abnormalities, age, drug addiction, neuropsychiatric disorders, and surgery play a role in the etiology of colonic volvulus, and the main predisposing factor for this condition is a high-fiber diet (9). In this study we have seen an elongated and mobile sigmoid colon, and a narrowed and fibrotic sigmoid mesentery in most cases. Although a preponderance of males among sigmoid volvulus patients has been reported, the male:female ratio in previous reports was interestingly different (10). In this report, a 3.2-fold incidence was seen in males. Sigmoid colon volvulus is usually a disease of the aged. The age distribution of our cases was similar to that of previous reports $(11,12)$.

The signs and symptoms of our patients were similar to those of previous reports $(7,12)$. Physical examination revealed distension with obstructive bowel sounds in the majority of cases, and the diagnosis may be confirmed in those patients where a dilated loop of distended colon can be seen coming to a point in the left iliac fossa or pelvis on plain abdominal radiographs (6). The diagnosis in the present series was established preoperatively in 70 percent of patients, a percentage similar to that reported in other series (13).

Endoscopic procedures and intubation of the sigmoid colon are very important in the evaluation of sigmoid volvulus. The initial management of acute, nonstrangulated sigmoid volvulus is to insert a rigid rectosigmoidoscope and attempt the passage of a soft, flexible tube through the volvulated segment. But this procedure has a high perforation risk. Still, detortion procedures for this series were performed with a rigid rectosigmoidoscope (n = 24) until 1994. We also had three cases where a colon perforation occurred, and the success rate was low $(42 \%)$. However, in the last seven years this procedure was accomplished with the aid of a colonoscope $(n=15)$

Table II. Postoperative complications

\begin{tabular}{|c|c|c|c|c|c|c|c|}
\hline & $\begin{array}{l}\text { Wound } \\
\text { infection }\end{array}$ & $\begin{array}{c}\text { Cardio-respiratory } \\
\text { problems }\end{array}$ & Diarrhea & $\begin{array}{c}\text { Wound } \\
\text { dehiscence }\end{array}$ & Fistula & Bleeding & $\begin{array}{l}\text { Urinary } \\
\text { infection }\end{array}$ \\
\hline Operative detortion $(n=17)$ & 5 & 6 & 1 & 2 & 1 & - & 1 \\
\hline Hartmann's procedure $(n=19)$ & 4 & 3 & 1 & 2 & 1 & 1 & 1 \\
\hline Primary resection $(n=6)$ & 2 & 3 & - & - & 1 & - & - \\
\hline Elective resection $(n=19)$ & 2 & 2 & - & - & 1 & - & - \\
\hline
\end{tabular}


and no complications were related to this procedure, while the success rate increased to $60 \%$. The flexible colonoscope has brought considerable advantages to the diagnosis and nonsurgical treatment of volvulus, as its air-feeding property and flexibility help clinicians in the detortion phase. A colonoscope also gives a chance to visualize the proximal segments of the colon before surgery, and prevents that possible concomitant conditions be missed. The better viewing potential of a colonoscope is also helpful for the clinician when attempting to differentiate between a viable and non-viable bowel.

Laparotomy should be undertaken if there is an ulcerated or necrotic mucosa at endoscopy, or if the bowel is inadvertently damaged. Recurrence rates of 30-90\% after non-operative reductions of a sigmoid volvulus were previously reported. According to previous reports, leaving a rectal tube in the rectum for more than 48-72 hours, and an elective colon resection within 1-10 days are necessary measures (14). We also left the tube at least 48 hours.

When a viable bowel is confirmed at surgery, a variety of surgical procedures are possible. Since operative detortion with or without colopexy has a very high recurrence rate (15), we believe that at emergency laparotomy a resection of the sigmoid loop is neccessary. The Mikulicz resection has been advocated for as the operation of choice (1). The main disadvantage of this procedure is that only a limited colonic resection can be carried out distally. The resection must include the neck of the volvulus and when this is close to the rectum, an extensive mobilization may be necessary to allow the distal limb of the colostomy to be brought up without tension. This may be impossible. In our patients treated with emergency surgery the mortality rate was $21 \%$. This rate was higher than the rate for patients with non-operative treatment followed by elective resection (5.2\%). These results were similar to those of previous reports (16).
We concluded that an initial therapy using endoscopy affords decompression and an adequate preparation of patients for surgical resection, and that a flexible colonoscope has notable advantages over rigid instruments in the detortion process.

\section{REFERENCES}

1. Bolt DE. The management of volvulus of the sigmoid colon. Br J Surg 1956; 44: 172-5.

2. Wertkin MG, Aufses AH. Management of volvulus of the colon. Dis Colon Rectum 1978; 21: 40-5.

3 . Nay HR, West JP. Treatment of volvulus of the sigmoid colon and cecum. Arch Surg 1967; 94: 11-3.

4. Hines JR, Geurkink RE, Bass RT. Recurrence and mortality rates in sigmoid volvulus. Surg Gynecol Obstet 1967; 124: 567-70.

5. Drapanas T, Stewart J. Acute sigmoid volvulus. Am J Surg 1961; 101: 70-1.

6. Anderson JR, Lee D. The management of acute sigmoid volvulus. Br J Surg 1981; 68: 117-20.

7. Oncu M, Piskin B, Calik A, Yandi M, Alhan E. Volvulus of the sigmoid colon. S Afr J Surg 1991; 29: 48-9.

8. Dulger M, Canturk NZ, Utkan NZ, Gonullu NN. Management of sigmoid colon volvulus. Hepatogastroenterology 2000; 47: 1280-3.

9. Ballantyne GH. Review of sigmoid volvulus. Clinical patterns and pathogenesis. Dis Colon Rectum 1982; 25: 823-30.

10. Udezue NO. Sigmoid volvulus in Kaduna, Nigeria. Dis Colon Rectum 1990; 33: 647-9.

11. Theuer C, Cheadle WG. Volvulus of the colon. Am Surg 1991; 57: 145-50.

12. Geer DA, Arnaud G, Beitler A, Holcomb J, Homan J, James L, et al. Colonic volvulus. The Army Medical Center experience 1983-1987. Am Surg 1991; 57: 295-300.

13. Young WS, Engelbrecht HE, Stoker A. Plain film analysis in sigmoid volvulus. Clin Radiol 1978; 29: 553-60.

14. Oraja EA. Sigmoid volvulus in Kenyatta National Hospital. 19761980. E Afr Med J 1983; 60: 290-6.

15. Sutcliffe MM. Volvulus of the sigmoid colon. Br J Surg 1968; 55: 903-10.

16. Siroospour D, Berardi RS. Volvulus of the sigmoid colon: a ten-year study. Dis Colon Rectum 1976; 19: 535-41. 